\title{
Smart Use of Smart Phones in Classrooms - Interrupt Fun to Educate
}

\author{
Ahmad Hammoud, Ahmad Shatila and Nisrine Adada \\ Global University, Lebanon
}

\begin{abstract}
Nowadays, technology is invading our homes and schools. Teenagers, children, and even babies are attached to smart devices and their apps. Parents and teachers are trying to resist this trend as they believe their children are spending a lot of time playing and having fun with these devices. They think the more the children play, the less time they have for studying. The researchers decided to go against this trend and came up with a new concept called IF2E (Interrupt Fun to Educate). They developed a special app called KidKit to be installed on smart devices. It allows the teacher or the parent to create a test of several questions of different format on a specific subject. The child will be given the smart device with KidKit installed and running. S/He will not be able to close or stop the KidKit app because it is password protected. The app will ask the child a question; when the correct answer is provided, the child will be rewarded and KidKit will open his/her favorite game for a minute. After this, another question will pop up, and the cycle is repeated every minute until the test is over. The researchers introduced KidKit to four sections of grade six studying programming. The students were evaluated with and without KidKit using four different exams. A one-way ANOVA was used to compare the results. The results showed that KidKit had a positive effect on student achievement.
\end{abstract}

\section{Introduction}

Educators use any possible approach to make knowledge available to learners. They take advantage of any method to help students learn. Using digital games is considered an excellent method through which students can learn a lot because they are attracted to these games [1]. Moreover, Squire pointed out that the educational potential games had was not only cognitive, but also social [2].

Games could support as well as accelerate students' learning processes [3]. They help students develop a sense of community [4]. Moreover, they help the students construct disciplinary knowledge as well as teach them professional skills [5]. It is a common trend among all generations to have some fun while playing games, using applications, watching videos, listening to music, or even chatting with others. Some educators decided to create special educational games to teach their students. They wanted to benefit from the fact that these digital native students are fond of technology and especially digital games [6]. In January 2013, Apple announced that users have downloaded more than 40 billion applications with nearly 20 billion in 2012 alone [7].

According to PC Magazine, MobiThinking, IntoMobile, Google, Apple, Microsoft, and Blackberry, the top categories of downloaded apps were as follows [8]:

Table 1. Top Categories of Downloads

\begin{tabular}{|c|c|c|}
\hline Rank & Category & $\%$ of total downloads \\
\hline 1 & Games & $23 \%$ \\
\hline 2 & Entertainment & $11 \%$ \\
\hline 3 & Utilities & $10 \%$ \\
\hline 4 & Education & $7 \%$ \\
\hline
\end{tabular}

As Table1 shows, Games and Education together formed around $30 \%$ of all apps downloaded. This shows how passionate users are to play games. Furthermore, Lenhart, Kahne, Middaugh, Macgill, Evans, and Vitak stated that $97 \%$ of US teens play a certain type of digital game on regular basis [9].

\section{Digital games for educational purposes}

Educators have been using games for educational purposes since the $18^{\text {th }}$ century; however, in the recent decades and because of the rapid advancement in technology, digital games are now being employed in the classrooms [10]. Many educators have advocated the use of digital games in educational settings for many reasons, some of which are: cognitive and affective learning [11]. "In a survey by the Joan Ganz Cooney Center, $60 \%$ of K-8 teachers who use digital games said that since integrating digital games into the classroom their students had become better collaborators and paid greater attention to specific tasks. Fifty-six percent said lower-performing students were now more engaged with the content" [12]. Moreover, according to Yang, children who used digital devices were more motivated to learn [13]; thus becoming active in their own learning process [14]. Teachers usually use extrinsic motivation (grades) to encourage their 
students to learn; games, however, instill intrinsic motivation in students because they are enjoyable experiences for them; they are fun [15] and [12]. Another reason digital games motivate students is that they are user-centered designs that arouse students' interest and give them power to express themselves freely [16]. In addition, Demb, Erickson, and Hawkins-Wilding reported that students positively perceived the impact of their use of digital devices on their academic success as well as their study habits [17]. Thus, there is a growing interest in the applicability of digital games in education [18].

\subsection{Assessment}

Several studies have been done to test the effect of using games as formative assessment tools [19]. However, little research exists on the use of digital games as summative assessment tools [20]. Moreover, assessment has been integrated in digital games in a variety of ways, some of which are: quests, quizzes, and peer-assessment; the quizzes were of different formats (multiple choice questions, true/false, and fill-in-the blanks) and they were integrated at different levels or stages of the games[21].

Furthermore, digital games can give the students and the teachers immediate, direct feedback. This helps the students in their personalized learning, and helps the teachers differentiate instruction according to students' needs. "According to the Cooney survey, $62 \%$ of surveyed teachers said digital games made it easier for them to teach students of different abilities and to personalize instruction"[12].

The researchers planned to take advantage of these findings in order to encourage students to learn. Previously, many educators tried to do the same but with one major difference. They decided to develop new educational games that make the students have fun and learn at the same time. The researchers believed that this approach had many drawbacks and suggested a new way called IF2E to overcome these problems. These drawbacks areas are as follows. First, too many games are needed to cover all topics of one subject matter, in only one grade level. What about all subject matters in all grade levels? Second, developing digital games costs a lot of money[22]. Third, the development of a digital game may require years because of testing, refinement, and enhancements. Fourth, children acceptance of the game might be an issue; they might simply not like it. Fifth, parents cannot manipulate the content of the educational game to better cater for their children's needs. As stated before, IF2E attempts to solve all the above problems. IF2E does not require developing new games. This would save a lot of effort, time, and money.

In 2012, Entertainment Software Association has published a statistical report entitled "Essential Facts about the Computer and Video Game Industry"[23]. In this report, a lot of statistics and facts show how much users are attached to games. Below are some facts retrieved from this report:

- The average U.S. household owns at least one dedicated game console, PC or smartphone.

- $\quad 84 \%$ of parents place time limits on video game playing.

- $52 \%$ of parents say video games are a positive part of their child's life.

- $66 \%$ of parents believe game play provides mental stimulation or education.

- Consumers spent on Game industry around $\$ 24.75$ billion in 2011 .

\section{What is IF2E?}

Each child has his/her own way of having fun. To some of them, watching the Disney channel is the favorite way of having fun. Others prefer to play a certain video game which might be considered boring to others. This led the researchers to think of ways to establish a common system that caters for different students' needs.

Nowadays, children's fun activities have changed from outdoor to indoor because of the presence of digital devices [24]. IF2E is an approach that encourages educators and parents to make use of this children's favorite way of having fun in order to educate them. As mentioned above, the development of educational games requires a lot of time and money. Educators, designers, and developers might work on a game for years but eventually children might not like it and abandon using it. Although thousands of games have been developed, only few of them "survived", so why bother spend money, time, and effort to develop new educational games that might not be accepted! Instead, let's invest in IF2E that guides educators to detect each child's favorite digital game and then use it to teach him/her. Instead of using games as teaching tools, the IF2E uses games for motivation. Students will be prompted to concentrate more on the lessons or the tasks they have because this will ensure them more playing time and thus more fun. In IF2E students will be provided with digital devices that they can use to play games or watch videos. They will be allowed to use these devices for a certain time but their usage will be interrupted by academic questions or tasks. In order to continue using these devices they will need to answer the questions or complete the tasks. This way students' fun (using the digital devices) will be interrupted (by academic questions or tasks) to educate students. The following is a typical scenario:

An educator might have 20 students in class equipped with digital devices (tablets, or smart phones). He/she knows that 10 of these students like 
to play Subway Surfers on IPad, 6 prefer to watch cartoons, and 4 like to explore Google Earth. This educator can split the class into 3 groups so that each group can do what they like the most. KidKit, an application developed by the researchers to implement IF2E, will be installed on all devices used by the kids. While watching or playing, the fun will be interrupted by KidKit. A popup screen will appear asking a question prepared by the educator. The students will not be able to proceed unless they provide the correct answer. At this point, they ask each other, refer to their books, or even consult their teacher. This process will encourage them to search for the correct answer, revise their lessons, and learn from one another. The fact that they are attached to watching Disney or playing a game will motivate them to make some effort in order to overcome the current obstacle, finding the correct answer.

Moreover, parents can use IF2E at home with their children by adding revision questions to their children's favorite games then allowing them to play. This way children will be playing their favorite games and learning math, English, science, geography, history, or even foreign languages at the same times. Parents will thus encourage their children to play rather than ask them to stop playing! A typical scenario might be:

A child is at home studying for an upcoming math exam. The mother wants to help him/her study. She asks the child about his/her favorite game. After the child tells her which game she/he likes to play, the mother uses KidKit to add the math revision questions to the game the kid chose. She then allows the child to play the game. Every minute the game will be interrupted by one of the revision questions. If the child answers correctly she/he is given the chance to continue playing. On the other hand, if they answer incorrectly, they cannot continue playing. Here the mother steps in to help her child in math. She can reteach a specific skill or correct a misconception. She then can allow the child to take a second chance by playing the game again.

\section{KidKit}

\subsection{Features}

The educator or parent will be able to determine the interval of seconds that specifies when the popup screen appears. By default, a new question will pop up every minute.

The child can provide a wrong answer only once. If a wrong answer is given twice, the whole process is terminated and the student will not be allowed to proceed. This way, students are encouraged to do their best to provide the correct answers. The popup screen will hide anything that was running before so that access to the previous application is not allowed. This screen will never close unless the correct answer is provided. Even when the child clicks the home screen, KidKit will detect this and the popup screen will appear again.

The question the educator asks might include hints that will help the students find the correct answer. The hints might refer the students to a certain paragraph in their books, an internet URL, a video to watch, or another book to read.

Educators can supply questions of the types presented in Table 2.

Table 2. Types of Questions

\begin{tabular}{|c|c|}
\hline Type & Sample Question \\
\hline Exact Text & $\begin{array}{l}\text { What is the name of the planet } \\
\text { closest to Earth? }\end{array}$ \\
\hline Single & $\begin{array}{l}\text { Which of the following is an } \\
\text { animal: }\end{array}$ \\
\hline Choice & $\begin{array}{l}\bigcirc \text { car } \bigcirc \text { circle } \bigcirc \text { monkey } \bigcirc \\
\text { pen }\end{array}$ \\
\hline & Which of the following is a country: \\
\hline Choice & $\begin{array}{l}\square \text { Asia } \square \text { tree } \square \text { triangle } \square \\
\text { USA }\end{array}$ \\
\hline True/False & $\begin{array}{l}\text { Napoleon Bonaparte was born in } \\
1769\end{array}$ \\
\hline Sorting & $\begin{array}{l}\text { Sort according to area: } \\
\text { USA, Italy, Lebanon }\end{array}$ \\
\hline Matching & $\begin{array}{l}\text { Link each animal to its food (rabbit, } \\
\text { lion, bird) \& (meat, carrots, seeds) }\end{array}$ \\
\hline
\end{tabular}

Educators can also run KidKit using "teacher mode" where they can import a new set of questions, create a new exam, change settings, or even specify the game/app that the students like to use. KidKit also allows educators to specify what happens when the student supplies a correct answer. The first option allows the student to proceed to the next question. If this is the case, KidKit is used as a testing tool without any other fun application. The other options allow the students to go back to their favorite game/app.

In case the student does not know which answer is right, KidKit provides the "assist" feature which will tell him/her which answer is the correct one. The educator specifies how many times the student can be "assisted". Without this feature, the order of the questions is critical because the student might get blocked after answering one question wrongly and will not be allowed to proceed although s/he might know the answers of the rest of the questions. To overcome this blocking nature, KidKit can be set to "assist" the student by informing him/her of the correct answer. At the end of the exam, the student will be told how many points s/he missed/gained. 


\subsection{Technical Challenges}

Developing KidKit is a real challenge as a high level of control is needed over the smart phone. KidKit should override any running applications and open on top of them. It should also prevent users from using home and back buttons to make sure they are stuck with the current question. Doing all of this on Android devices was not hard. Nonetheless, this was not the case with IOS application because no control is given to the developer outside the boundaries of the application. After one month of experiments and tests, the researchers decided not to develop an IOS version of KidKit, which is available for Android-based devices only.

\section{Benefits of IF2E}

Many parents strive to minimize the time their children spend using tablets and smart devices because they think that it is a waste of time. Although the parents choose certain apps for their children, the children might not like these apps and find other alternatives. This is the heart of the problem tackled in this research: the children do not choose the apps; their parents do. With KidKit, the children choose the app and the parents control it.

With IF2E, the more the children use smart devices, the more they are educated. Suppose that a child used a tablet with KidKit installed for an hour. His/her parents should be happy as their child has answered 60 academic questions. The researchers believe that parents should not discourage students to use digital devices. They should instead, make such devices work for them not against them. That is, make them part of their learning process.

Furthermore, IF2E might help students who have test anxiety due to the fact that it integrates fun into the test which helps relieve stress. IF2E encourages educators and parents not to resist the smart phones anymore. Instead, they have the chance to take advantage of such a tool. With IF2E, the more kids use smart phones, the more they are being educated.

\section{Implementation of IF2E}

\subsection{Sampling and Instrument}

In a previous research done by the researchers[25], the efficiency of teaching programming languages to grade five, six, and seven students was studied. This research has been going on for the past two years. It first started as a summer program and when research showed promising results the researchers decided to take it one step further and try it in a regular scholastic year. A new subject- programming literacy- was introduced and set as a part of the academic curriculum of the fifth and sixth grades in two Lebanese schools. One session per week was allocated for the program and a trained teacher was chosen for the job. Grade five students were taught the HTML language while grade six students were taught HTML and SQL. The researchers then used this ongoing research to try IF2E and study its effects. Four sections, 80 students, from one of those schools were selected. Four exams, each made of 15 items from the format presented in Table 2, were conducted over the period of four weeks. Each week the students sat for an exam in a different way as presented in Table 3.

Table 3. List of Exams

\begin{tabular}{|l|l|l|}
\hline Exam & Description & Date \\
\hline \multirow{2}{*}{1} & $\begin{array}{l}\text { Paper-based exam } \\
\text { Traditional way }\end{array}$ & $\begin{array}{l}18 \mathrm{Jan} \\
2014\end{array}$ \\
\hline \multirow{2}{*}{2} & $\begin{array}{l}\text { Exam using KidKit. } \\
\text { Game included + no assists }\end{array}$ & $\begin{array}{l}25 \mathrm{Jan} \\
2014\end{array}$ \\
\hline \multirow{2}{*}{3} & Exam using KidKit. & $01 \mathrm{Feb}$ \\
& Game NOT included +2 assists & 2014 \\
\hline \multirow{2}{*}{4} & Exam using KidKit. & 08 Feb \\
& Game included +2assists & 2014 \\
\hline
\end{tabular}

In the first week, the students were told at the beginning of the session that they would be tested at the end of the session. So, at the end of the session they were presented with a paper-based exam compromised of 15 questions. Students were given 7 minutes to complete the exam and then the exams were graded.

In the second week, the same thing was repeated but with the introduction of KidKit. Students were also told that they were going to be tested but using mobile phones this time. The teacher finished the session and then gave the students Android-Based mobile phones and introduced them to KidKit. Students were playing Subway Surfers (a wellknown game for the students) and every 30 seconds students were interrupted with a question.

If the student failed to answer one question he/she was not allowed to continue the game nor the exam. The students were given 10 minutes to complete 15 questions and play at the same time. When a student was blocked the teacher took the phone and recorded his/her grade.

In the third week, the researchers realized the blocking effect of KidKit and decided to change its features. The assist feature was added, this feature would allow students to skip a question and continue other parts of the exam. Instead of students stopping at the first question they failed to answer correctly, students were given the chance to get the answer from the program and move on. They were allowed to do that twice in the course of the exam.

The students were told at the beginning of the session that they would sit for an exam using the mobile phones. They were not told that the exam 
would not be merged with the game. At the end of the session, each student took a mobile phone and started the exam. The exam time was 7 minutes and students were not blocked, since they were allowed to use the assist feature twice, until the y failed three questions. Students were also given 15 questions and were graded according to the questions they got right and not the ones they got assistance for.

The fourth week was a merge between the procedure used in the second week and the one used in the third week. Students were told that they would sit for an exam at the end of the session and that they would use their phones. They were not told that the exam was going to be merged with the game. At the end of the session, the students sat for a 15-question, 10-minute exam using KidKit.

The students were playing Subway Surfers again and every 30 seconds a question stopped them. If they knew the answer, they would continue; if they did not, they were allowed to ask the program for it (only twice). At the end the grade was recorded also based on the right answers only.

\subsection{The results}

The results of the four exams are as follows. The maximum grade for all 4 exams was 15 points. In Exams 3 and 4, the number of "assists" used was deducted from each student's final grade; so for example, if a student scored 15 with 2 assists his/her grade was entered as 13. A one-way ANOVA was used to compare the grades of the four exams and the results are presented in Tables $4 \& 5$, and in Figure 1. The results of Exam 2 were higher than those of Exam 1, but no statistical difference was found. The results of Exams 3 and 4 were both statistically higher than those of Exams 1 and 2. The results of Exams 3 and 4 were almost identical. It is worth noting that the results of Exam 1, the paper-based exam, were the lowest amongst the set of exams conducted.

Table 4. Exam Averages

\begin{tabular}{|l|l|l|l|l|}
\hline Exam & $\mathrm{N}$ & \multicolumn{1}{|c|}{ Mean } & $\begin{array}{c}\text { Std. } \\
\text { Deviation }\end{array}$ & Std. Error \\
\hline 1.00 & 77 & 8.5844 & 3.10496 & 0.35384 \\
\hline 2.00 & 70 & 9.6571 & 5.56096 & 0.66466 \\
\hline 3.00 & 75 & 11.5867 & 3.40942 & 0.39369 \\
\hline 4.00 & 77 & 11.5844 & 3.72174 & 0.42413 \\
\hline Total & 299 & 10.3612 & 4.21128 & 0.24354 \\
\hline
\end{tabular}

Fig.1 shows the mean of grade related to each exam. The curve shows a big difference between the first 2 exams and the last ones.

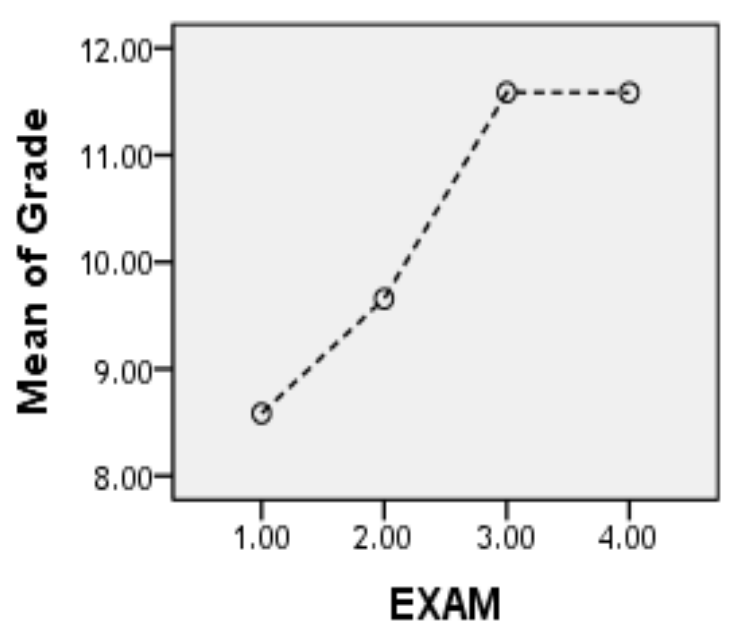

Figure 1. Averages

Table 5 compares each exam to the other three and shows the mean difference, the standard error, and the significance.

Table 5. Multiple Comparisons

\begin{tabular}{|c|c|c|c|c|}
\hline EXAM & EXAM & $\begin{array}{c}\text { Mean } \\
\text { Difference }\end{array}$ & Std. Error & Sig. \\
\hline \multirow{3}{*}{1} & 2 & -1.07273 & 0.66472 & 0.372 \\
\hline & 3 & $-3.00225^{*}$ & 0.65301 & 0.000 \\
\hline & 4 & $-3.00000^{*}$ & 0.64870 & 0.000 \\
\hline \multirow{3}{*}{2} & 1 & 1.07273 & 0.66472 & 0.372 \\
\hline & 3 & $-1.92952^{*}$ & 0.66893 & 0.022 \\
\hline & 4 & $-1.92727^{*}$ & 0.66472 & 0.021 \\
\hline \multirow{3}{*}{3} & 1 & $3.00225^{*}$ & 0.65301 & 0.000 \\
\hline & 2 & $1.92952^{*}$ & 0.66893 & 0.022 \\
\hline & 4 & .00225 & 0.65301 & 1.000 \\
\hline \multirow{3}{*}{4} & 1 & $3.00000^{*}$ & 0.64870 & 0.000 \\
\hline & 2 & $1.92727^{*}$ & 0.66472 & 0.021 \\
\hline & 3 & -0.00225 & 0.65301 & 1.000 \\
\hline
\end{tabular}

\subsection{Discussion of Results}

The first exam was a traditional paper-based one. The grades were generally low as the average was 8.6 out of 15 , which is around $57.3 \%$. The students were told at the beginning of the exam that they will be tested so they were triggered to concentrate. Although the material they were studying (HTML language) was interesting it was not motivating enough for them to pay full attention.

The second exam was different, and the students were also informed about its nature, that is the students were told that they would use mobile phones to play and get tested at the same time. This motivated them to concentrate more on the 
explanation. The idea of being able to use mobile phones in class and also playing a digital game in class was simply electrifying for students. Students were very interested in the lesson and tried to pay close attention since that would decide the amount of fun they would have. The average increased from 8.6 to 9.7 , which is from $57.3 \%$ to $64.6 \%$ in the second exam. Although this was not a statistically significant difference, the researchers believed that this increase was due to the use of KidKit. It is important to mention that in Exam 2 students who made a mistake were forced to stop the exam and were not given the chance to try solving the rest of the questions. So if a student missed question 5 his/her grade would be 4 and he/she was not allowed to even look at the rest of the questions which he/she might have known the answers for. Thus the grade could have been higher had the student tried solving all the questions. In general the researchers believed that the enthusiasm that the kids showed at the start of the lecture allowed them to pay more attention to what the teacher explained, thus affected their results positively.

In the third trial- the third exam- the researchers tried to overcome the blocking effect of KidKit by introducing the assist feature that was discussed earlier. The researchers also tried to see if there was a difference between having a game and not having one during assessment. It was decided to use KidKit with no game (only questions) in the third week and to do the same in the fourth week but with the inclusion of the Subway Surfer game. So in the third week students only answered questions using KidKit which was installed on Android based mobile phones, while in the fourth week, students played and their play time was interrupted by questions they had answer. The third exam showed considerable improvement. The average of the third exam was 11.6 which is $77.3 \%$; that was higher than the earlier averages of $57.3 \%$ and $64.6 \%$. The average has risen although no game was used. The students were using the mobile phones as a testing tool without playing a game. The students saw the phones at the beginning of the lecture and concentrated on the material expecting to play with the phones. They were not told that there would be no game to play at the end of the session. This motivation was coupled with the use of two "assists" to decrease the blocking effect of KidKit.

The fourth exam showed the same results as its predecessor. It was so obvious that the students did a great job as they moved from $57.3 \%$ to $77.3 \%$. The last exam was not as easy as the previous ones. It included topics that were considered by the students as "the hardest." The last exam was the "toughest" exam for students and still they managed to get much better grades.

Looking at the results in general, one can see that students achieved better using KidKit. The researchers came to the conclusion that informing the students about the use of KidKit motivated them to concentrate more on the lecture. Furthermore, the game feature itself affected their motivation positively. This is confirmed by what Demirbilek reported that mobile games, due to the rapid changes of technology, are becoming very popular among students, regardless of their age [26]. Many students were excited to do the test mainly because of the game. This finding goes hand in hand with what was reported by Phillips and Popović [27]. They stated that game-based assessment helped teachers motivate students to better achieve.

The results of Exam 4 were a clear indicator of this aspect. The positive attitude the students displayed because of the use of the digital devices and the game confirms with the results found by Abdul Razak \& Thomas [28]. Many previous approaches tried using games to assess students [29]. The researchers' approach was different in the way it was introduced. They decided to use games as a motivation technique for students to pay attention in class. The results showed that this lead to better student achievement on summative assessment.

\section{Conclusion}

IF2E has many advantages which are mainly the disadvantage of the alternative (educational games):

i) It does not require developing new educational games that need a lot of time and money.

ii) It uses already existing games chosen by the students themselves, while in educational games one needs to develop exercises and games for various skills and objectives.

iii) Parents and teachers are involved by specifying the questions and setting the exams which might not be the case with educational games.

The researchers concluded, based on the results they found in this study, that the implementation of IF2E had a positive effect on students' motivation as well as their academic achievement. When the students realized that they were to use mobile phones, and KidKit, in the exams, their concentration on the lecture given was higher than when no KidKit was implemented. IF2E takes advantage of whatever the students like, whether it is a game, a video, a TV channel, or any application. Instead of building games and hoping to gain children's acceptance, IF2E calls for using what has already been accepted. 


\section{Future Work}

IF2E seems to be a promising approach in education. A lot of work still has to be done. The researchers plan to apply the KidKit idea to Smart TVs, Interactive Boards, and Games Boxes, such as Xbox and Play Station. The researchers have been using the KidKit as a summative assessment tool. Next step would be to use it for formative assessment. The KidKit will be integrated into the classroom as part of the teacher's teaching strategies. For instance, students will be put in groups of 4 to 5 and they will be given a strategy game to play all together. After playing for few minutes, the students will be given cooperative exercises to solve. Their fun- game playing- will be interrupted by exercises that they have to solve collaboratively. They thus will be learning and having fun at the same time. Although this is going to need a lot of effort, time and money, the academic benefit might exceed our expectations.

\section{Acknowledgements}

The researchers would like to thank AICP for supporting this research line and allowing the researchers to use a lot of AICP school resources. They also gratefully acknowledge the efforts of Ms. Rana Dimashkiya who taught the four sections. The researchers would also like to thank the developers who created KidKit for all the efforts they made. At last but not least, they appreciate the contributions of the staff of Global University, especially the department of Computer Science.

\section{References}

[1] de Freitas, S., Savill-Smith, C., \& Attewell, J. (2006). Educational games and simulations: Case studies from adult learning practice. London: Learning and Skills Research Centre.

[2] Squire, K. (2002). Cultural framing of computer/video games. Game Studies 2. Retrieved from: http://www.gamestudies.org/

[3] Klabbers J. (2003). The gaming landscape: a taxonomy for classifying games and simulations. In Level Up Digital Games Research Conference (eds M. Copier \& J. Raessens), pp. 54-67. University of Utrecht, Utrecht, the Netherlands.

[4] Abbott, M., (2010). Portal on the booklist. Retrieved from:

http://www.brainygamer.com/the_brainy_gamer/2010/08/p ortalbooklist.html.

[5] Söbke, H., Bröker, T., \& Kornadt, O. (2013). Using the Master Copy: Adding educational content to commercial video games. Proceedings of the European Conference on Games Based Learning, p521-530.
[6] Prensky, M. (Oct., 2001) Digital natives, digital immigrants. On the Horizon, 9, (5), 1-6.

[7] Miller, T. \& Monaghan, C. $(2013,1,7)$. App Store Tops 40 Billion Downloads with Almost Half in 2012. Retrieved April 2, 2014, from https://www.apple.com/pr/library/2013/01/07App-StoreTops-40-Billion-Downloads-with-Almost-Half-in2012.html

[8] Statistics Brain, (Feb, 2014). Mobile Phone App Store Statistics. Retrieved April 2, 2014, from http://www.statisticbrain.com/mobile-phone-app-storestatistics/

[9] Lenhart, A., Kahne, J., Middaugh, E., Macgill, A. R., Evans, C., \& Vitak, J. (September, 2008). Teens, video games, and civics. Retrieved from the Pew Internet \& American Life Project Web site http://www.pewinternet.org/Reports/2008/Teens-VideoGames-and-Civics.aspx

[10] Bopp, M. M. (2008). Storytelling and motivation in serious games. Final Consolidated Research Report of the EnhancedLearning Experience and Knowledge Transfer Project(ELEKTRA), (European Commission contract number027986). Retrieved from http://ocw.metu.edu.tr/pluginfile.php/4624/mod_resource/c ontent/0/ceit706/week8/MatthiasBopp.pdf

[11] O’Neil, H. F., Wainess, R., \& Baker, E. L. (2005). Classificationof learning outcomes: Evidence from the computergames literature. Curriculum Journal, 16 (4), 455-474.

[12] Phillips, V. \& Popovic, Z. (2012, Oct.). More than child's play:Games have potential learning and assessment tools. Phi Delta Kappan, 94 (2), 26-30.

[13] Yang, Y. C., (Sep, 2012). Building virtual cities, inspiring intelligent citizens: Digital games for developing students' problem solving and learning motivation. Computers \& Education, 59 (2), 365-377.

[14] Prensky M. (2003) Digital game-based learning. ACM Computersin Entertainment, 1, 21-24.

[15] Hong, J., Cheng, C., Hwang, M., Lee, C. \& Chang, H. (2009,Oct.). Assessing the educational values of digital games. Journal of Computer Assisted Learning, 25 (5), 423-437.

[16] Frenouillet F. (2003) La Motivation. Les Topos. DunodÉditeur, Paris.

[17] Demb, A., Erickson, D. and Hawkins-Wilding, S. (2004). The Notebook Alternative: Student's Reactions and Strategic Implications, Computers and Education, 43, 383-401.

[18] McClarty, K. L., Orr, A., Frey, P. M., Dolan, R. P., Vassileva, V. \& McVay, A. (June, 2012). A Literature Review of Gaming in Education: Pearson. 
[19] Wang, T. H. (2008) Web-based quiz-game-like formative assessment: development and evaluation, Computers and Education, 51, 1247-1263.

[20] Charlier, N. \& Clarebout, G. (2009). Game-based assessment: Can games themselves act as assessment mechanisms? A case study. Proceedings of the European Conference on Games Based Learning, p404-411.

[21] Chaudy, Y., Connolly, T.,\& Hainey, T. (2013). Specification and design of a generalized assessment engine for GBL applications. Proceedings of the European Conference on Games Based Learning, p105-114.

[22] Klopfer, E., Osterweil, S., \& Salen, K. (2009). Moving learning games forward: obstacles, opportunities, and openness. The Education Arcade: Massachusetts Institute of Technology, 1-56.

[23] ESA, (2012). Essential facts about the computer and video game industry. Retrieved April 2, 2014, from http://www.theesa.com/facts/pdfs/esa_ef_2012.pdf

[24] Dwyer, J. (2007). Computer-based learning in a primary school: Differences between the early and later years of primaryschooling. Asia-Pacific Journal of Teacher Education,35 (1), 89-103.

[25] Hammoud, A; Shatila, A.; Adada, N., (2013) "Incorporating Programming Literacy in the Curriculum of Grades: 5, 6, 7 ", ICERI 2013 Proceedings, p.474-482.

[26] Demirbilek, M., (2010). Investigating attitudes of adult educators towards educational mobile media and games in eight European countries. Journal of Information Technology Education, 9, 235-247.

[27] Phillips, V. \& Popvić, Z. (Oct., 2012). More than child's play: Games have potential learning and assessment tools. Phi Delta Kappan, 94 (2), 26-30.

[28] Abdul Razak, A. \& Thomas, C. (Jan., 2013). Using games for learning, from the students' perspectives. Proceedings of the European Conference on Games Based Learning, p706-713.

[29] McAlpine, M., van derZanden, L., Harris, V. (2010). Using games based technology in formal assessment of learning. Proceedings of the European Conference on Games Based Learning, p242-250. 